EGU21-7581, updated on 05 May 2021

https://doi.org/10.5194/egusphere-egu21-7581

EGU General Assembly 2021

(c) Author(s) 2021. This work is distributed under

the Creative Commons Attribution 4.0 License.

\title{
Irradiance and atmospheric optical properties from photovoltaic power data: model improvements and first results
}

\author{
James Barry ${ }^{1,2}$, Dirk Böttcher ${ }^{1}$, Johannes Grabenstein ${ }^{1}$, Klaus Pfeilsticker ${ }^{1}$, Anna Herman-Czezuch' \\ Nicola Kimiaie ${ }^{2}$, Stefanie Meilinger ${ }^{2}$, Christopher Schirrmeister ${ }^{2}$, Felix Gödde ${ }^{3}$, Bernhard Mayer ${ }^{3}$, \\ Hartwig Deneke ${ }^{4}$, Jonas Witthuhn ${ }^{4}$, Philipp Hofbauer ${ }^{5}$, and Matthias Struck ${ }^{5}$ \\ ${ }^{1}$ University of Heidelberg, Institute of Environmental Physics, Physics and Astronomy, Heidelberg, Germany \\ ${ }^{2}$ International Centre for Sustainable Development, Hochschule Bonn-Rhein-Sieg, Sankt Augustin \\ ${ }^{3}$ Meteorological Institute, Ludwig-Maximilians-University, Munich \\ ${ }^{4}$ Leibniz Institute for Tropospheric Research, Leipzig \\ ${ }^{5}$ egrid applications \& consulting $\mathrm{GmbH}$, Kempten
}

Photovoltaic (PV) power data are a valuable but as yet under-utilised resource that could be used to characterise global irradiance with unprecedented spatio-temporal resolution. The resulting knowledge of atmospheric conditions can then be fed back into weather models and will ultimately serve to improve forecasts of PV power itself. This provides a data-driven alternative to statistical methods that use post-processing to overcome inconsistencies between ground-based irradiance measurements and the corresponding predictions of regional weather models (see for instance Frank et al., 2018). This work reports first results from an algorithm developed to infer global horizontal irradiance as well as atmospheric optical properties such as aerosol or cloud optical depth from PV power measurements.

Building on previous work (Buchmann, 2018), an improved forward model of PV power as a function of atmospheric conditions was developed. As part of the BMWi-funded project MetPVNet, PV power data from twenty systems in the Allgäu region were made available, and the corresponding irradiance, temperature and wind speed were measured during two measurement campaigns in autumn 2018 and summer 2019. System calibration was performed using all available clear sky days; the corresponding irradiance was simulated using libRadtran (Emde et al., 2016). Particular attention was paid to describing the dynamic variations in PV module temperature in order to correctly take into account the heat capacity of the solar panels.

PV power data from the calibrated systems were then used together with both the DISORT and MYSTIC radiative transfer codes (Emde et al., 2016) to infer aerosol optical depth, cloud optical depth and irradiance under all sky conditions. The results were compared to predictions from the COSMO weather model, and the accuracy of the inverted quantities was compared using both a simple and more complex forward model. The potential of the method to extract irradiance data over a larger area as well as the increase in information from combining neighbouring PV systems will be explored in future work. 


\section{References}

Buchmann, T., 2018: Potenzial von Photovoltaikanlagen zur Ableitung raum-zeitlich hoch aufgelöster Globalstrahlungsdaten. Heidelberg University, http://archiv.ub.uniheidelberg.de/volltextserver/24687/.

Emde, C., and Coauthors, 2016: The libRadtran software package for radiative transfer calculations (version 2.0.1). Geosci. Model Dev., 9, 1647-1672, doi:10.5194/gmd-9-1647-2016. https://www.geosci-model-dev.net/9/1647/2016/.

Frank, C. W., S. Wahl, J. D. Keller, B. Pospichal, A. Hense, and S. Crewell, 2018: Bias correction of a novel European reanalysis data set for solar energy applications. Sol. Energy, 164, 12-24, doi:10.1016/j.solener.2018.02.012. https://doi.org/10.1016/j.solener.2018.02.012. 